\title{
DIREITO À CIDADE E O PRINCÍPIO DE PROIBIÇÃO DE RETROCESSO
}

\author{
CARLOS ALBERTO MOLINARO*
}

RESUMO: O presente ensaio expõe algumas reflexões do autor sobre o Direito Fundamental à Cidade, como um direito fundamental e como um direito humano na perspectiva socioambiental, e a incidência do Princípio de Progressividade na concretização dos Direitos Sociais, Econômicos, Culturais e Ambientais, além da Proibição de Retrocesso dos DESCA já concretizados neste privilegiado espaço de convivência.

PALAVRAS-CHAVE: Direitos Fundamentais; Direitos Humanos; Cidade; Cidadania; Princípios Fundamentais; Progressividade e Proibição de Retrocesso.

ABSTRACT: This essay presents some author's reflection concerning the Right to the City as Fundamental Right, and as Human Right in the socio-environmental perspective, and the incidence of the Progressive Principle realization of Economic, Social, Cultural, and Environmental Rights (ESCER), besides the Non-Retrogression Principle of the ESCER already implemented on this privileged space of coexistence.

KEYWORDS: Fundamental Rights; Human Rights; City; Citizenship; Fundamental Principles; Progressive Principle and Non-Retrogression Principle.

SUMÁRIO: Introdução; 1. O Direito à Cidade: direito humano e direito fundamental; 2. A ocupação dos espaços urbanos na perspectiva da socioambientalidade; 3 . A dimensão cidadã na urbe e o seu toporama; 4 . O espaço urbano e à progressiva concretização dos direitos humanos, a exigibilidade dos direitos fundamentais no direito brasileiro relativamente ao direito à cidade e a cidadania; 4.1. O dever de concretização gradual dos direitos humanos; 4.2. A aplicação imediata dos direitos sociais e o princípio de proibição de retrocesso, na perspectiva do direito brasileiro; Algumas reflexões finais; Referências.

SUMMARY: Introduction; 1. The Right to the City: human rights and fundamental rights; 2 . The occupation of urban spaces in the socio-environmentalist perspective; 3. The citizenship dimension in the urbe and its toporama; 4. Urban space and the progressive realization of human rights, the enforceability of fundamental rights under Brazilian Law with reference to the right to the city and citizenship; 4.1. The duty of progressivity to realization of human rights; 4.2. Immediate application of social rights and the non-retrogression principle in the perspective of Brazilian Law; Some final thoughts; References.

Artigo recebido em $1^{\circ} .03 .2010$ e aprovado para publicação pelo Conselho Editorial em 30.03.2010.

* Doutor em Direito. Professor na PUCRS na Graduação e no Programa de Mestrado e Doutorado em Direito. Professor permanente no Programa Oficial de Mestrado/Doutorado em Direitos Humanos e Desenvolvimento da Universidade Pablo de Olavide (Sevilha, Espanha). 


\section{INTRODUÇÃO}

Hay ciudades secretas dentro de cada ciudad. Las ciudades secretas están construidas por instantes de tiempo encendido, por fugacidades luminosas. Son, pues, fugitivas, y muy difíciles de fotografiar, pero todos las hemos sentido alguna vez: ciertas y misteriosas, alucinadas y poderosamente intensas.

David Eloy Rodríguez ${ }^{1}$

Identificar um direito à cidade conduz o observador para a reflexão sobre como estão formatadas as cidades de nossos dias, sobre como as condições de vida nelas têm sido degradadas seja pela privatização desordenada dos bens e dos serviços, seja pelo continuado aumento dos níveis de desigualdade, da cada vez mais visível discriminação e da consequente exclusão provocada; portanto, importa também, considerar l'état d'art na concretização dos direitos humanos e dos direito fundamentais que digam com o direito à cidade.

A cidade a concebeu Italo Calvino ${ }^{2}$ como cidade invisível, isto é, cidades que são patrimônio da imaginação, pois para o autor as cidades insinuam a grande metáfora da criação e interpretação humana. A tese principal na novela de Calvino está em que as cidades, com sua complexidade arquitetônica, social e ideológica encruzadas, são o que os homens fazem a si mesmos, sua revelação, sua fenomenologia; logo, todas as cidades, as que existiram, as que existem e, também as por existir, se podem imaginar uma vez que se fazem conhecidas suas regras mais primárias; as cidades invisíveis são, portanto, cidades que existem na imaginação, são lugares de experiência simbólica que se revelam na felicidade e no sofrimento daqueles que as interrogam. Desde outra perspectiva, Paolo Cottino ${ }^{3}$ a concebeu como cidade imprevista, isto é, nos apresenta três historias cujas narrativas se dão nas cidades de nossos dias: a ocupação de edifícios abandonados, a espontaneidade social e a diversidade cultural dos grupos em um mercado informal, ademais da luta dos mais desassistidos e, em especial dos mais velhos e aposentados na defesa de um pequeno terreno urbano para vê-lo transformado em uma moradia permanente. Esses espaços residuais e anônimos definidos por sujeitos coletivos desde estas três histórias rebatem em um ponto de partida para uma reflexão sobre o significado dos comportamentos urbanos afetados, que na maioria das vezes surgem da condição de privação e da capacidade imaginativa para encontrar soluções alternativas distintas das tradicionais. Cidades invisíveis ou imprevistas estão presentes nos espaços urbanos de nossas cidades contemporâneas, de nossas metapolis que se organizam - na feliz expressão de José A. Cuerda Montoya ${ }^{4}$ - como arquipélagos urbanos ou como contêineres de vizinhos. Esta cidade - produto cultural - emerge de processos históricos, de transformações e de desenvolvimento, de equívocos e de acertos. Espaço físico, social e simbólico onde se conforma o público

${ }^{1}$ RODRÍGUEZ, David Eloy, et al. Asombros, Sevilla: Imagoforum, 2006.

${ }^{2}$ CALVINO, Italo. Le città invisibili, Milano: Mondadori, 1993.

${ }^{3}$ COTTINO, Paolo. La città imprevista. Il dissenso nell uso dello spazio urbano, Milano: Elèuthera Editrice, 2003.

${ }^{4}$ CUERDA MONTOYA, José Ángel. Hacia una nueva cultura política, in, Derechos Humanos y Tolerancia, Pablo J. Beltrán de Heredia Iraurgui (coord.), San Sebastian: Real Sociedad Bascongada de Amigos del País, 2000. 
por excelência, e o cívico por antonomásia, mas também uma cidade degradada onde o cívico se converte no incívico, o álacre em deprimente. Enfim, um espaço onde deve ser buscada a máxima vantagem social e a liberdade cidadã, refutando, deste modo, a segregação social, a degradação ambiental, e, finalmente, a infelicidade. Esta é a cidade que nos interessa no presente ensaio.

\section{O DIREITO À CIDADE: DIREITO HUMANO E DIREITO FUNDAMENTAL}

1. Todas las personas tienen derecho a la ciudad sin discriminaciones de género, edad, condiciones de salud, ingresos, nacionalidad, etnia, condición migratoria, orientación política, religiosa o sexual, así como a preservar la memoria y la identidad cultural en conformidad con los principios y normas que se establecen en esta Carta.

2. El Derecho a la Ciudad es definido como el usufructo equitativo de las ciudades dentro de los principios de sustentabilidad, democracia, equidad y justicia social. Es un derecho colectivo de los habitantes de las ciudades, en especial de los grupos vulnerables y desfavorecidos, que les confiere legitimidad de acción y de organización, basado en sus usos y costumbres, con el objetivo de alcanzar el pleno ejercicio del derecho a la libre autodeterminación y un nivel de vida adecuado. El Derecho a la Ciudad es interdependiente de todos los derechos humanos internacionalmente reconocidos, concebidos integralmente, e incluye, por tanto, todos los derechos civiles, políticos, económicos, sociales, culturales y ambientales que ya están reglamentados en los tratados internacionales de derechos humanos. Esto supone la inclusión de los derechos al trabajo en condiciones equitativas y satisfactorias; a fundar y afiliarse a sindicatos; a seguridad social, salud pública, agua potable, energía eléctrica, transporte público y otros servicios sociales; a alimentación, vestido y vivienda adecuada; a educación pública de calidad y la cultura; a la información, la participación política, la convivencia pacífica y el acceso a la justicia; a organizarse, reunirse y manifestarse. Incluye también el respeto a las minorías y la pluralidad étnica, racial, sexual y cultural y el respeto a los migrantes. El territorio de las ciudades y su entorno rural es también espacio y lugar de ejercicio y cumplimiento de derechos colectivos como forma de asegurar la distribución y el disfrute equitativo, universal, justo, democrático y sustentable de los recursos, riquezas, servicios, bienes y oportunidades que brindan las ciudades. Por eso el Derecho a la Ciudad incluye también el Derecho al Desarrollo, a un medio ambiente sano, al disfrute y preservación de los recursos naturales, a la participación en la planificación y gestión urbana y a la herencia histórica y cultural.

Carta Mundial pelo Direito à Cidade

(Foro Social de las Américas, Quito, Julio 2004; Foro Mundial Urbano, Barcelona, Quito, Octubre 2004; Foro Social Mundial, Porto Alegre, Enero 2005)

O sociólogo Robert Ezra Park já afirmou que a cidade é o desígnio mais exitoso do ser humano de fazer e refazer o mundo em que vive de acordo com o seu desejo mais íntimo. Mas, se a cidade é o mundo que o ser humano criou, é também o mundo em que a partir de agora está condenado a viver. Portanto, indiretamente e sem um 
sentido nítido da natureza de sua tarefa ao fazer a cidade o ser humano se refaz a si mesmo $^{5}$. Neste sentido, aceitando a proposta de Park, sobre a capacidade de fazer e refazer as cidades, concomitantemente com o fazer e refazer das características de seres humanos contingentes, pode-se aceitar que o direito à cidade é um dos mais importantes dos direitos humanos, todavia, o que mais tem sido negligenciado.

A Carta Mundial pelo Direito à Cidade, acima referida, no seu artigo primeiro atribui a todos o direito à cidade. Um direito que vai mais além da liberdade individual, mais além do acesso aos recursos urbanos, um direito, na acepção de Park, de transformação, e de construção de identidade e de sua requalificação, transformando e requalificando a cidade. Por isso mesmo, mais ainda que um direito individual revela-se como um direito social, comum a todos, pois todo o processo de transformação e requalificação leva de modo inexorável ao aprendizado do exercício do poder coletivo objetivando melhores condições urbanísticas para a convivência. Assim, este direito humano, também social, pois atribuído a um sujeito plural (todos) que se singulariza no individuo (o citadino), cabe no direito fundamental (constitucional), mas dele extravasa pelo seu conteúdo e natureza. Aqui, e para um só efeito, tomamos direitos humanos, não como direitos fundamentais positivados na ordem internacional, mas como produtos socioculturais imbricados em processos de lutas para a aquisição da dignidade, dignidade a ser concretizada em um cronotopos bem definido: a cidade. De outra parte, entendidos os direitos humanos como direitos positivados no direito das gentes eles coincidem, em grande parte, com os direitos fundamentais positivados nas ordens constitucionais, no caso brasileiro, até mesmo por força do $\S 2^{\circ}$ do Art. $5^{\circ}$ da Constituição de 1988, eles integram - bem como o superveniente ao articulado no $\S 3^{\circ}$ do mesmo dispositivo, realizado o ali disposto - à matéria constitucional.

O direito humano à cidade é um direito social, ademais de um direito de desfrute individual. Os direitos humanos são direitos de desfrute individual, todavia para sua concretização necessária a luta por eles, o que se faz coletivamente, envolvendo o social, o cultural, o ambiental e o político em processos emancipatórios cujas conquistas os conferem de forma comunitária. Esta dimensão social está presente nos movimentos sociais reivindicatórios, na política partidária, nas lutas associativas, sindicais e, também, na avaliação da situação desses direitos na ambiência da cidade, e sua permanente construção, assim como nos dessemelhantes grupos sociais que a integram ${ }^{6}$; para sua concretização exige a ocupação de um espaço, um lugar privilegiado, um espaço urbano socioambiental.

2. A OCUPAÇÃO DOS ESPAÇOS URBANOS NA PERSPECTIVA DA SOCIOAMBIENTALIDADE

A multidimensionalidade do espaço urbano está diretamente vinculada à natureza das ações humanas desenvolvidas sobre a cidade. Há uma dimensão espacial física, uma sociocultural, uma simbólica e uma dimensão espacial pública. Cada uma destas

${ }^{5}$ PARK, Robert E., On Social Control and Collective Behavior: Selected Papers (The Heritage of Sociology), Chicago: University of Chicago Press, 1967, p. 3.

${ }^{6}$ Em sentido semelhante, Zigmund BAUMAN, Community: Seeking Safety in an Insecure World, Cambridge: Polity Press, 2001, p. 88 e ss. 
especiais características do espaço urbano alberga diferentes - mas complementares - perspectivas socioambientais. A dimensão espacial física da urbe configura-se no território onde os processos urbanísticos se dão, isto é, sua conquista e o processo histórico deste: a planificação, a infraestrutura, os equipamentos urbanos, as moradias, etc., pois é nesta dimensão que se expressa e convive a cidadania. A dimensão espacial sociocultural, por sua vez, revela o cenário onde ocorrem, sobre o espaço físico, as relações inter-humanas dos habitantes da cidade, breve modo, relações sociais ${ }^{7}$, nesta cabe tudo, o amor, o ódio, o prazer e o desprazer, o trabalho e o ócio, a inclusão e a exclusão, a conservação e a degradação, a organização e a desorganização... $\mathrm{Na}$ dimensão espacial simbólica estão - sobre o resultado das relações socioculturais - alojadas as instituições, públicas, privadas, mistas, mas também, em outra percepção, os estabelecimentos de todos os tipos, a família, a escola, as seitas de qualquer espécie... Todavia, na dimensão espacial pública a cidade se revela mais claramente como objeto de direito, pois o espaço público é espaço cívico, é o espaço onde se assenta a comunidade política e onde tem lugar uma bolha de consenso que torna possível o empoderamento ${ }^{8}$ dos cidadãos e a juridicidade das relações de poder.

No direito positivo brasileiro, o direito à cidade é um direito fundamental decorrente do caráter socioambiental a que adere a república brasileira confortada em um Estado Democrático. A perspectiva socioambiental a que nos referimos trata de unir os reclamos sociais e ambientais para uma existência digna. Tem o mais elevado objetivo constitucional previsto nos Artigos 225 e $1^{\circ}$ da Carta da República e, relativamente às cidades, o disposto no Artigo $2^{\circ}$ e incisos da Lei ${ }^{\circ}{ }^{\circ} 10.257 / 2001$. $\mathrm{O}$ direito fundamental socioambiental à cidade, ainda que não esteja expressamente elencado nos tipos contidos no Artigo $5^{\circ}$ e incisos da Cidadã, por força do seu

\footnotetext{
${ }^{7}$ Como devemos qualificar a "relação social"? Pontes de Miranda (Sistema de Ciência Positiva do Direito, tomo IV, Editor Borsoi, Rio de Janeiro, 1972) é pontual: em qualquer caso ela é "relação de adaptação", contudo, alerta que há outras relações de adaptação que não são sociais, por isto afirma que "se a definimos como a relação de adaptação entre os homens entre si, ou entre eles e a sociedade, ou entre eles e os vários círculos sociais, ou dos círculos sociais entre si, estará definido com relativa precisão o fenômeno social” (p. 18). ${ }^{8}$ Intento de traduzir a expressão empowerment que denota a metódica da ação coletiva exercida pelos indivíduos quando compartilham espaços privilegiados de decisões e desenvolvem a consciência dos direitos sociais, ascendem à liberdade e à informação que permite a participação ativa na sociedade. Essa metódica suplanta a simples iniciativa individual para compreender e conformar as complexas redes de relações sociais que formatam os contextos culturais, jurídicos, econômicos e políticos, promovendo rapidez, flexibilidade e capacidade de decisão na organização dos interesses públicos primários. Reconhece-se, é claro, nem sempre ser possível a participação diretamente nas discussões sobre todos os detalhes de todos os tipos de políticas. Algumas políticas podem ser mais favoráveis à participação direta, outras podem requerer participação indireta através de representantes. Assim, a participação será, necessariamente, de forma diversa, mas o ponto essencial é que deve haver instituições que permitam uma verdadeira participação do povo na formulação das políticas públicas. Para que uma verdadeira participação seja possível, a cidadania deve ter poderes para reclamar os seus direitos e participar efetivamente no processo de tomada de decisão. O processo de empoderamento em si pode ser complexo e demorado, devido à natureza profundamente enraizada das assimetrias de poder que existe na maioria das sociedades. Ademais, um efetivo processo de empoderamento implica o reconhecimento da complementaridade entre direitos políticos e civis, por um lado, e econômicos, sociais, culturais e ambientais; por outro lado, acrescenta um novo impulso ao processo de fortalecimento e alargamento do âmbito das estratégias de redução das desigualdades. Em particular, isso ajuda a dissipar o equívoco de que direitos políticos e civis e das liberdades são luxos e relevante apenas para sociedades relativamente afluentes.
} 
parágrafo segundo, consubstancia-se, entre outras, na garantia da ocupação do urbano, no direito social à moradia e ao saneamento ambiental, à infraestrutura urbana, transportes e serviços públicos, ao trabalho, a saúde, ao lazer e a cultura, para as gerações presentes e futuras (inciso I, do Artigo $2^{\circ}$ da Lei ${ }^{\circ} 10.257 / 2001$ ), todos esses direitos e as respectivas garantias fundamentais são decorrentes do regime e dos princípios constitucionais. Portanto, à semelhança do direito fundamental ao meio ambiente ecologicamente equilibrado, o direito à cidade nele contido, também se revela como um direito entre gerações, inclusivo e social. Ademais e pela mesma razão, dá ensejo ao exercício pleno da cidadania e aos pertinentes deveres cometidos ao poder público.

\section{A DIMENSÃO CIDADÃ NA URBE E SEU TOPORAMA}

Cidadania $^{9}$ é uma qualidade atribuída a um sujeito de direito identificado e localizado no espaço político-jurídico, o que se traduz numa série de direitos, deveres, pretensões, obrigações, ações e exceções, na célebre divisão senária de Pontes de Miranda, relativos aos vínculos que conectam o cidadão a um espaço geopolítico definido e juridicamente densificado. Contudo, reconhecer tal qualidade não basta. Se precisa ir mais além. Ir ao conceito de relação. E, fornece a etimologia algumas pistas, relação de relatio (onis) é a ação de dar em retorno um fato, uma idéia, de e para um grupo, um a outro, etc., por conseguinte, o "relacional" se revela numa necessária interdependência de dois ou mais objetos pensados por um só sujeito que os interroga, ou na inderrogável conexão entre dois ou mais sujeitos que coexistem e que proclamam, entre si, o respeito, a reciprocidade e a responsabilidade; ou, na face negativa, o desprezo, o egocentrismo e a insensatez. Portanto, a cidadania se perfaz no campo do multifacetado caráter humano, e comporta inter-relações ${ }^{10}$ humanas as

${ }^{9}$ A cidadania conforma um status, vale dizer, um reconhecimento social e jurídico pelo qual uma pessoa, qualquer pessoa, tem direitos e deveres pela simples inclusão em uma comunidade, costumeiramente, de base territorial e cultural. Os cidadãos e cidadãs são iguais entre eles, não se pode distinguir entre cidadãos de primeira, de segunda, etc. No mesmo território, todos estão submetidos às mesmas leis, devem ser iguais em respeito e dignidade. A cidadania admite a diversidade, não a desigualdade. Observe-se que a cidadania se origina nas cidades, ali podemos identificá-la, caracterizada pela densidade, diversidade, normas não formais de convivência, multiplicidade de desejos, necessidades, abertura ao exterior... Pois, a cidade é intercambio permanente, ações, indústria, comércio, serviços e cultura. Não é somente "urbe", no sentido de concentração física de pessoas e equipamentos urbanos. É "civitas", lugar do civismo, ou participação nos quefazeres públicos. É "polis", lugar de política, de exercício efetivo do poder. Sem instituições fortes e representativas não há cidadania. $\mathrm{O}$ status, os direitos e deveres reclamam instituições públicas densificadas para garantir o exercício ou o cumprimento dos mesmos. A igualdade requer ação pública permanente, as liberdades urbanas suportam mal as exclusões que geram as desigualdades econômicas, sociais ou culturais. A cidadania vai estreitamente conectada com a democracia representativa para poder realizar suas promessas (Cf., sobre o tema BORJA, Jordi. Movimientos sociales urbanos Buenos Aires: Ediciones Siap-Planteos: Distribuidor exclusivo, Ediciones Nueva Vision, 1975; La ciudad conquistada. Madrid: Alianza Editorial, 2003; Urbanismo en el siglo XXI: Bilbao, Madrid, Valencia, Barcelona. Barcelona: Ediociones UPC, 2004. Ainda, FRANCISCO DIAZ, Andres de. Ciudadania y Democracia: un enfoque republicano. Madrid: La Catarata, 2006). ${ }^{10}$ Toda inter-relação está sustentada por ações e outras manifestações que obedecem a determinadas regras, e, por isso, se tornam inteligíveis. Ao obedecer a determinadas regras adquirem características significativas. $\mathrm{O}$ direito é um mecanismo de adaptação das relações inter-humanas havidas num espaço social em um dado lapso temporal, como instrumento adaptativo, é utilizado como exercício de um poder simbólico por determinados membros do estrato social dominante. Ao obedecer as regras, nossas palavras e nossas ações, no contexto dos papéis que desempenhamos face aos outros, e em correlação com os papéis representados por esses outros, nossas palavras implicam significância (valor), sendo, portanto, as relações 
mais variadas e, por isso mesmo, apresenta diversificadas reações agonísticas ${ }^{11}$ que se dão no espaço sociocultural das cidades.

A cidadania é também - na perspectiva objetiva do direito - um dos fundamentos sobre o qual repousa a estrutura estatal brasileira (Art. $1^{\circ}, \mathrm{II}-\mathrm{CF} / 88$ ), fato que conduz para a inafastabilidade do princípio que a contém. O princípio da cidadania implica na prática cotidiana e permanente de manifestações políticas dos cidadãos (atribuídos de tal qualidade). Uma verdadeira pedagogia dos direitos fundamentais [e humanos] nos espaços públicos, na família, no trabalho, na escola e na vida comunitária em geral, o que exige a participação no âmbito das decisões políticas ou administrativas que comprometem a cidadania, seja no singular ou no plural.

O exercício da cidadania exige, pois, um lugar. Um ambiente onde efetivamente se exerçam direitos, deveres, pretensões, obrigações, ações e exceções da participação cidadã. Em outro momento já afirmamos, na perspectiva socioambiental, que ambiente, incluída a clássica divisão: natural, artificial ou construído, social e cultural - é um "lugar de encontro"12. A ação cidadã se dá neste lugar de encontro ${ }^{13}$. Um espaço privilegiado da prática social, cultural e política: a cidade. Atente-se que o exercício

daí emergentes, relações significativas, isto é, portadoras de um sentido representativo do tecido social. Através da institucionalização do comportamento significativo dos atores sociais, as ideias e os valores do universo simbólico (ou cultural) ganham positividade ou vigência histórico-social. Ter vigência histórica significa atuar no plano social. A vigência é, com efeito, a forma de existência da ideia valorativa. É a positivação ou institucionalização histórica das ideias, ou valores normativos, nos diz o que vale e o que não vale, o que é correto e incorreto. A nossa visão do mundo, a concepção da vida, os nossos sentimentos e atitudes, modos de agir e reagir, enfim, todo o nosso comportamento são profundamente determinados por valorações e normas institucionalizadas e, sobretudo por aquelas interiorizadas em nossa socialização primária, quando da formação de nossa personalidade básica.

${ }^{11}$ Os vínculos sociais, de um modo geral são "invisibilizados" por um contraste que se estabelece entre antagonismo e agonismo. Veja-se que em ambas as expressões, o núcleo é o antepositivo grego agón

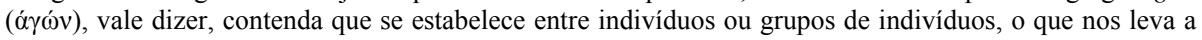
afirmar: entre inimigos e adversários, pois antagonistas são aqueles que fazem forte oposição aos que se lhes opõem; já os agonistas, são simples adversários que lutam pelas suas competências (como nos jogos), sem, contudo, levarem-nas as últimas consequências, admitindo serem nelas, vencidos. O mesmo se pode pensar na comparação dos termos gregos pólemos ( $\pi$ ó $\lambda \varepsilon \mu \mathrm{s} \varsigma$ ) e pólis ( $\pi$ ó $\lambda \mathrm{i} \varsigma$ ) que bem pode expressar o que está subjacente em o político e a política, isto é, o antagonismo (pólemos) fica superado pelo "viver em conjunto" próprio da pólis; o político é sempre antagônico, a política é sempre conciliação e neutralização das hostilidades próprias do antagonismo construtor das identidades coletivas.

${ }^{12}$ MOLINARO, Carlos Alberto, Direito Ambiental - Proibição de Retrocesso, Porto Alegre: Livraria do Advogado Editora, 2007. Ambiente é um lugar de encontro das condições bióticas e abióticas que possibilitam à existência, esta oração substitui, porque inclusiva, todo o articulado no texto constitucional art. 225, incisos e $\S 1^{\circ}, \mathrm{I}, \mathrm{VII}$; art. $215, \S 1^{\circ}$ e $\S 2^{\circ}$; art. 182; art. 21, XX; art. 5 , XXIII; art.7, XXII; art. 200, VIII, e na ambiência infraconstitucional, o art. $3^{\circ}$, I, da Lei $n^{\circ} 6.938 / 81$.

${ }^{13}$ Concebido "ambiente" como um lugar de encontro, esta concepção leva junto o etimológico do substantivo/ adjetivo: ambiente. Como ensina Ávila Coimbra (Cf. AVILA COIMBRA, J. de, O outro lado do meio ambiente. 2. ed. Campinas: Millenium Editora, 2002, p. 25, nota 9), ambiente está composto por duas propostas latinas $a m b(0)$ que induz a ideia de "andar à volta", ao redor, e o verbo ire, ir, donde $a m b+$ ire = ambire, vale dizer, ambiente é tudo o que vai à volta, o que rodeia determinado ponto ou ser. Este "andar à volta", este lugar de encontro (substantivo), mesmo, do encontro (verbo flexionado) com o outro e os demais seres bióticos e abióticos, exige permanência e manutenção (ação de manter, ou de segurar com a mão), reclama a efetividade do princípio de proibição da retrogradação socioambiental. Por isso, se pode entender o princípio e seu objeto, a vedação da degradação ambiental, como informador, também, de uma ecocidadania responsável, como uma razão mesológica que viabiliza a existência de um mínimo ecológico. 
da cidadania, na perspectiva da sua inclusão na soberania do Estado, e mesmo na do Estado-membro que a conforta, se dá, de modo efetivo e concreto, no espaço urbano, no Município, este é o ente visível onde o cidadão, consciente ou inconscientemente, nasce, vive e morre. Por isso mesmo, por tal qualidade de cidadania, dimensionada no citadino, é conferido, entre outros, o direito ao lugar, um espaço onde fixa seu domicílio, sua residência e seu entorno inclusivo das relações que estabelece, neste lugar reclama por políticas de desenvolvimento urbano, ou exige a reabilitação de áreas degradadas ou marginais; ademais, do direito à mobilidade e a acessibilidade, indispensável para fazer concretas as liberdades urbanas, isto é, tornar possível a utilização das oportunidades sociais, econômicas, e culturais que a cidade oferece. $\mathrm{E}$, neste sentido, avulta o direito à qualidade do meio ambiente urbano, que inclui o uso dos recursos naturais e energéticos, o acervo histórico-cultural e, especialmente, a proteção frente às agressões advindas da contaminação (de qualquer origem), do congestionamento dos fluxos (de qualquer curso), da inadequação arquitetônica, da miséria e da exclusão na participação dos espaços públicos.

\section{O ESPAÇO URBANO E À PROGRESSIVA CONCRETIZAÇÃO DOS DIREITOS HUMANOS, A EXIGIBILIDADE DOS DIREITOS FUNDAMENTAIS NO DIREITO BRASILEIRO RELATIVAMENTE AO DIREITO À CIDADE E A CIDADANIA}

A cidade revela um ecossistema preenchido por interações socioculturais que intercambiam informações entre si. Sob a perspectiva informacional a cidade incorpora uma singular população associada a complexos processos de informação compartida sobre uma base geopolítica, sua posição e morfologia, bem como, funções urbanas imbricadas desde específicas necessidades humanas e o seu papel histórico. Neste contexto, as cidades devem contar com um espaço urbano-socioeconômico diverso, o que demanda do poder local a introdução de políticas de planificação urbana, sociocultural e econômica mediante novas práticas na gestão da urbe, tudo com a finalidade de obter maior diversidade, riqueza e sustentabilidade de seu território.

Tal objetivo exige cada vez mais informação, sempre atualizada e em tempo real, sobre o status quo e o progresso dos qualificados aspectos atinentes ao desenvolvimento urbano, desde um ponto de vista integral de desenvolvimento sustentável em termos de planejamento urbano, econômico e socioambiental. A informação, neste caso, é a pedra de toque para a tomada de decisões. Decisões que devem ser cada vez mais adequadas o que, contudo, na maioria das vezes enfrenta uma persistente debilidade de meios de informação, eficiência e demora nos processos. As angustiantes necessidades urbanas constrangem não só as autoridades locais, também os investidores e os prestadores de serviços que passam a trabalhar na cidade, muitas vezes, sem os meios de informação apropriados, o que produz inadequada coordenação e celeridade entre suas iniciativas. A gestão efetiva dos recursos de qualquer espécie, o progredimento e fomento da qualidade de vida na cidade e a progressiva abertura da sociedade, reclamam procedimentos fundamentais comuns para a integração e consequente sistematização da informação urbana ${ }^{14}$.

${ }^{14}$ No mesmo sentido, e em profundidade, cf. CASTELLS, Manuel, The Rise of the Network Society, 
O problema se agrava se o vincularmos ao princípio da progressiva concretização dos direitos econômicos, sociais, culturais e ambientais na ambiência dos direitos humanos ${ }^{15}$. Mediante o progressive principle como é mais conhecido da doutrina internacional, os Estados estão obrigados a tomar medidas com o objetivo de garantir progressivamente a plena realização dos direitos humanos, nas matrizes sociais, econômicas, culturais e ambientais, com o máximo dos recursos disponíveis ${ }^{16}$. Algumas obrigações de efeito imediato têm-se revelado difíceis de controlar. Estas incluem obrigações fundamentais para garantir, pelo menos, um nível mínimo de usufruto dos elementos essenciais aos direitos humanos, tais como o acesso aos alimentos, cuidados básicos de saúde, a moradia, a educação, o emprego, a segurança e a inclusão dos marginados. Outras obrigações se revelam em garantir o exercício dos direitos sem discriminação alguma, em especial para reduzir as disparidades decorrentes da injusta distribuição dos bens e serviços, fato que, na sua ausência, acarreta a cada vez maior exclusão e criminalidade, e onde? - Nas cidades. Todos esses eventos ocorrem efetivamente no espaço urbano das cidades ${ }^{17}$. Por conseguinte, é de se esperar uma progressiva concretização das condições materiais, e.g. infraestrutura, regulação, etc., hábeis ao pleno exercício do direito à cidade no amplo espectro da sociabilidade dos direitos humanos, aqui tomados como produtos socioculturais embutidos em processos emancipatórios cujas conquistas, step by step, vão acompanhando o desenvolvimento da cidade.

Massachusetts: Blackwell Publishers, 1996; The Informational City is a Dual City: Can It Be Reversed? High Technology and Low-Income Communities: Prospects for the Positive Use of Advanced Information Technology, Massachusetts: MIT Press, 1996.

${ }^{15}$ Deve-se levar em conta, que os direitos humanos são produtos culturais - construídos na história gestados nos processos emancipatórios permanentes pela conquista da dignidade humana, processos estes dependentes dos esforços comuns e, afinal, lograda sua realização são cristalizados pelo direito positivo.

${ }^{16}$ Quando falamos especificamente do sistema internacional de direitos humanos, não é de indivíduos, nem outros agentes, mas de Estados que livremente "contratam" entre si os diversos tratados de direitos humanos. Na condição de Estado Parte de um tratado internacional de direitos humanos, o convenente está legalmente obrigado, e eles (os Estados) concordam em ser monitorados em seu desempenho. De acordo com o sistema internacional de direitos humanos, a principal responsabilidade é a da proteção e realização dos direitos humanos. Isso significa sua concretização prévia a quaisquer outras considerações.

${ }^{17}$ Com efeito, estabelece o PDESC, Artigo $2^{\circ}$, 1 . Cada um dos Estados Partes no presente Pacto se compromete a adotar medidas, tanto por separado como mediante a assistência e a cooperação internacionais, especialmente econômicas e técnicas, até o máximo dos recursos de que disponha, para lograr progressivamente, por todos os meios apropriados, inclusive em particular a adoção de medidas legislativas, a plena efetividade dos direitos aqui reconhecidos. Uma leitura atenta do articulado leva a inferir que os Estados Convenentes obrigam-se a "adotar medidas", o que remete imediatamente ao comportamento a ser adotado pelos Estados no sentido cumprir com o pleno desfrute dos direitos assinalados no Pacto, e.g, a atuação política, legislativa, administrativa, judicial, econômica, social, educativa entre outras, inclusive na adaptação da legislação interna, com o objetivo de que sejam claramente compatíveis com os deveres pactuados, revogando aquelas que sejam incompatíveis com o Pacto. $\mathrm{O}$ mesmo se dá com a inferência: "até o máximo dos recursos que disponha", o que remete imediatamente à obrigação, no plano interno, no dever de alocar os recursos necessários às prestações devidas, e só neste caso, exauridas estas (via comprovação orçamentária e esgotadas as verbas legalmente asseguradas) alegar uma legitima "reserva do possível". Portanto, o Estado tem o dever de provar a insuficiência de recursos orçamentários para cumprir suas obrigações na satisfação dos DESCA, à exceção do mínimo exigível para uma vida com dignidade; ademais, deverá comprovar que realizou todo o esforço para satisfazer, prioritariamente, essas obrigações mínimas, inclusive com a ajuda internacional (órgãos de fomento). Em conclusão, a limitação de recursos não libera o Estado de sua obrigação de assegurar o desfrute mais amplo destes direitos. 
Contudo, esclareça-se, não estamos aqui defendendo o caráter programático das normas relativas aos direitos sociais do citadino no direito brasileiro que regula a matéria de modo mais amplo que o direito internacional. Fazemos questão de mencionar o dever (autônomo) dos Estados convenentes ao pacto - em sede de ius gentium de progressivamente tornar concreto e exigível o direito à cidade e as correlativas condições materiais para a fruição deste direito. E, no caso de sua concretização no espaço urbano, logicamente, ele está atrelado de modo progressivo, ao desenvolvimento da urbe. Portanto, no sistema brasileiro a progressividade se dá apenas e na medida do desenvolvimento de novas necessidades, sendo os direitos sociais fundamentais de aplicação imediata (na forma de sua tipologia), ademais, esta progressividade atrela o administrador público, bem como, a iniciativa privada que esteja vinculada a prestação de serviços públicos, assim como aquela que tem por objetivo a inversão financeira na transformação dos espaços urbanos edificáveis ${ }^{18}$. Esta vinculação é exigível, fluida de um processo social, político e legal. Deve ser observado, que o respeito e cumprimento dos direitos sociais e tout court das normas que os consagram, não são tão só devidos pelos órgãos competentes da administração (na matriz judiciária, legislativa ou executiva), mas envolve a participação ativa da sociedade civil como condição substancial do exercício da cidadania.

Por força da matriz de fundamentalidade dos direitos econômicos, sociais, culturais e ambientais no sistema brasileiro - incluindo-se aí o direito à cidade - são eles direitos subjetivos públicos cuja exigibilidade pode ser exercida individual ou coletivamente. Ademais, tal condição matricial, fixa o perímetro mínimo ${ }^{19}$ a que está obrigado o Estado a cumprir para garantir o funcionamento de sociedades justas e para legitimar sua própria existência. Para tanto, o Estado deve disponibilizar os meios indispensáveis e mandatórios para cobrir as mais prementes necessidades da população, e definir políticas publicas de progressiva (vale dizer, promover ou favorecer o progresso em direção a melhores condições e novas políticas, ideias ou métodos) melhora dos espaços urbanos das cidades e do nível de vida dos citadinos

${ }^{18}$ Cf., relativamente à eficácia entre terceiros dos direitos fundamentais, SARMENTO, Daniel, Direitos Fundamentais e Relações Privadas, Rio de Janeiro: Lúmen Júris, 2004. Sobre o tema indispensável à leitura dos diversos textos articulados pelo Prof. Ingo W. Sarlet, especialmente, A eficácia dos direitos fundamentais. Uma teoria geral dos direitos fundamentais na perspectiva constitucional (10. ed. Livraria do Advogado Editora, 2009).

${ }^{19}$ Aqui se tem de observar duas situações: uma que a doutrina, especialmente a internacional, reconhece como conteúdo essencial, ou "núcleo duro" ( minimum core content) dos DESCA; outra, o limiar mínimo (minimum threshold). A perspectiva do conteúdo essencial aponta para a posição central do articulado que confere o direito, e esta centralidade não pode ser violada, podemos encontrá-la "na razão de ser" do direito e, portanto, não pode ser objeto de quantificação (aí está a chave para identificar o núcleo duro de um direito fundamental: impossibilidade de medir a qualidade que se quer atribuir com o direito, uma noção abstrata que está intimamente atrelada à dignidade humana). Ao contrário, a perspectiva do limiar mínimo, ou o limite inferior tem endereço certo: concretizar e induzir conclusões operacionais ao cumprimento dos DESCA, isto é, revelar o vetor para a formulação das políticas públicas, relativas às decisões que o Estado está obrigado a tomar para o cumprimento do Pacto (DESCA), e neste sentido, e só neste, a adoção de modelos quantitativos hábeis para permitir a determinação do patamar mínimo de bemestar, ou de satisfação das necessidades (por todos cf., DOWELL-JONES, Mary. Contextualising The International Covenant On Economic, Social And Cultural Rights: Assessing The Economic Deficit. Leiden: Martinus Nijhoff Publishers, 2004). 
para o mais bem desfrute desses direitos. No campo da eficácia, esses direitos têm aplicação imediata ex vi de expresso mandamento constitucional (art. $5^{\circ}, \S 1^{\mathrm{o}}$, $\mathrm{CF} / 1988$ ), contudo, é de observar que o direito à cidade é um direito formado, mas em constante transformação quanto ao seu objeto, o que leva a diferir o campo da eficácia para cobrir as transformações de seu objeto ocorrentes no tempo e no espaço.

\subsection{O dever de concretização gradual dos direitos humanos}

Pelas reflexões alcançadas até o momento, observa-se que o tema comporta duas ordens de aproximação. Uma, com relação aos direitos humanos e ao direito à cidade como atribuídos, isto é, a progressiva implantação das condições materiais dependentes da evolução ou desenvolvimento dos espaços urbanos (ocupação, infraestrutura, regulação, etc.), o que exige uma prestação positiva do Estado, pois obrigado na ordem internacional à prática efetiva de políticas públicas, alocação de recursos econômico-financeiros, de pessoal, etc. outra, o direito à cidade, conferido à cidadania como direito fundamental positivado. Um direito subjetivo público de matriz social (conferido pelo direito objetivo) que se singulariza no indivíduo (atribuindo um direito subjetivo). Todavia, seja em uma ou outra aproximação, o princípio de progressividade arrogado à concretização dos diretos humanos na sua dimensão econômica, social, cultural e ambiental, ou a imediata eficácia dos direitos sociais positivados na Constituição brasileira - direitos esses que vão ser exercidos em um concreto espaço: o das cidades - vincula um mandamento inderrogável: a objeção de não regressividade das conquistas já alcançadas pelos sujeitos de direito no espaço socioambiental e jurídico brasileiro. Esta objeção está fundada no princípio de proibição do retrocesso ${ }^{20}$. Logo, tanto a gradatividade como a imediatividade de aplicação das normas, seja de direito internacional, ou do direito constitucional brasileiro

${ }^{20}$ Sobre o princípio de proibição do retrocesso, ver as agudas e judiciosas articulações de Ingo Wofgang SARLET, especialmente na $10^{\mathrm{a}}$ edição (revista, atualizada e ampliada) de seu A eficácia dos Direitos Fundamentais - Uma teoria geral dos Direitos Fundamentais na perspectiva constitucional (Porto Alegre: Livraria do Advogado Editora, 2009, p. 384 e ss.); também, Direitos Fundamentais Sociais e proibição de retrocesso: algumas notas sobre o desafio da sobrevivência dos direitos sociais num contexto de crise, in, VV. AA., (Neo)Constitucionalismo - ontem, os Códigos hoje, as Constituições, Revista do Instituto de Hermenêutica Jurídica, v. I, n. 2, Porto Alegre, 2004; O Estado Social de Direito, a Proibição de Retrocesso e a Garantia Fundamental da Propriedade. Revista Diálogo Jurídico. Salvador, CAJ-Centro de Atualização Jurídica, v. I, no 4, julho, 2001. Disponível em: <http:www.direito publico.com.br>, acesso em 12.04.2008; ainda, DE CONTO, Mario, O princípio da Proibição de Retrocesso Social - Uma análise a partir dos pressupostos da hermenêutica filosófica, Porto Alegre, Livraria do Advogado Editora, 2008; DERBLI, Felipe, O princípio da proibição de retrocesso social na Constituição de 1988, Rio de Janeiro: Renovar, 2007; MARTINS, Patrícia do Couto Villela Abbud, A proibição do retrocesso social como fenômeno jurídico, in: Garcia, Emerson (Coord.). A efetividade dos direitos sociais, Rio de Janeiro: Lumen Juris, 2004; MENDONÇA, José Vicente dos Santos, Vedação do retrocesso: o que é e como perder o medo, Revista de Direito da Associação dos Procuradores do Novo Estado do Rio de Janeiro, Rio de Janeiro: Lumen Juris, 2003. v. XII. p. 205-236; na doutrina comparada: CANOTILHO, José Joaquim Gomes. Constituição dirigente e vinculação do legislador: contributo para a compreensão das normas constitucionais programáticas, 2. ed. Coimbra: Coimbra Editora, 2001; MIRANDA, Jorge. Manual de Direito Constitucional, 5. ed. Coimbra: Coimbra Editora, 2003; QUEIROZ, Cristina, O princípio da não reversibilidade dos Direitos Fundamentais Sociais: princípios dogmáticos e prática jurisprudencial, Coimbra: Coimbra Editora, 2006; COURTIS, Christian, La prohibición de regresividad en materia de derechos sociales: apuntes introductorios, in Courtis (comp.), Ni un paso atrás. La prohibición de regresividad en materia de derechos sociales, Buenos Aires, Editores del Puerto, 2006. 
atraem o princípio da proibição de retrocesso, o que implica no "congelamento" das conquistas sociais consolidadas (inclusive as legislativas), ademais da vedação da diminuição dos níveis já alcançados de proteção destas conquistas.

Entretanto, observe-se que a progressividade na realização dos direitos humanos está intimamente vinculada à natureza humana, pois é natural do ser humano a inacabada progressão até mesmo pelo imperativo da preservação da espécie, daí o não retrocesso das condições pelas quais se dá esse conjunto de práticas, como o manejo planejado e programas de (re)produção, que visa à manutenção de populações ou espécies. Com as cidades ocorre igual, já que os espaços urbanos são ocupados pelos humanos, espaços em que ocorrem circuitos de reações culturais, entre eles, a busca dos bens e, também, de novos bens, para o preenchimento de necessidades sempre crescentes. Neste sentido, o processo de desenvolvimento é permanente e sucessivo, como consecutivas são as carências produzidas pelo déficit na conquista dos bens necessários.

A consecutio temporum, ou em vernáculo, a correlação do tempo entre a efetuação satisfazível das necessidades e a ausência desta realidade verificável implica violação aos direitos humanos. De outro modo, a correlação temporal produz o imperativo de manutenção das necessidades já atendidas, com o que se preserva a segurança das relações albergadas pelo direito. Como se vê, há um autêntico dever do Estado (um ente que se presenta e representa uma pluralidade de seres humanos) de proteção, e da mais ampla realização dos direitos atribuídos aos humanos, positivados ou objetiváveis na ordem internacional, ou na ordem local das constituições, proteção e concretização esta que vai sendo construída gradualmente, sempre e na medida da premência dos bens necessários a satisfação das necessidades.

\section{retrocesso $^{21}$ \\ 4.2. A aplicação imediata dos direitos sociais, e o princípio de proibição de \\ Os direitos fundamentais sociais - segundo a Constituição brasileira, na} interpretação que dela fazemos, na companhia de parte da literatura especializada gozam de aplicação imediata. $\mathrm{O}$ direito à cidade, como direito fundamental amplamente suportado pela sociabilidade das relações inter-humanas intercorrentes nos espaços urbanos tem aplicação imediata, tanto no que concerne a característica Socioambiental do Estado brasileiro onde se inclui, como, e especialmente, nos direitos derivados do seu exercício, e.g., entre outros, o direito a moradia, incluídas a propriedade territorial e os direitos relativos aos efeitos da posse, bem como, as políticas públicas de fomento a construção e financiamento de bens imóveis, especialmente aqueles menos favorecidos; o direito a segurança e o aparato necessário a sua concretização; o direito à saúde e a consequente prestação dos serviços necessários a seu efetivo exercício; o direito à mobilidade urbana e os meios indispensáveis que devem ser postos à disposição; o direito ao trabalho e a consequente oferta de trabalho pela iniciativa privada (até mesmo pelo mandamento do princípio de simetria entre capital e trabalho, previsto no inciso IV do art. $1^{\circ}$ da $\mathrm{CF} / 1988$ ), o que se faz em espaços

${ }^{21}$ Em língua inglesa, por todos, confira-se o trabalho de John C. Jeffries Jr. Daryl J. Levinson, The Non-Retrogression Principle in Constitutional Law, in, California Law Review, vol. 86, n. 6, 1998, p. 1211 e ss. 
urbanos dedicados; o direito ao lazer como implícito à dignidade atribuída ao humano, cujo exercício depende da alocação de especiais espaços públicos e seus equipamentos; o direito à educação e sua pertinente e complexa rede de ensino que o confere e instrumentaliza; o direito a cultura que inclui a beleza arquitetônica, os espaços públicos dedicados às artes de qualquer natureza, e os processos e padrões de comportamento, crenças, conhecimentos, costumes etc., que distinguem os diversos grupos sociais que habitam a cidade; o direito das presentes e futuras gerações à cidade não degradada, o que se alcança com políticas públicas eficientes na manutenção de um ambiente benfazejo à saúde e aprazível ao espírito.

Todos estes direitos, já formados, gozam da prerrogativa decorrente do princípio de não retrocesso do seu estado e estágio, e na perspectiva da proteção ambiental (das cidades), isto e, da prerrogativa decorrente do princípio de proibição da retrogradação socioambiental. Relativamente à vedação da alteração do estado alcançado, concorrem com o principio de proibição de retrocesso (isto é, proibição da retrogradação socioambiental), o princípio de proteção da continuidade ou da existência (Bestandsschutzprinzip), assim como o princípio de conservação ou manutenção do status quo (Prinzip der Status-quo-Erhaltung), ou ainda, o princípio de proibição da deterioração (Verschlechterungsverbot) ${ }^{22}$. Todas estas expressões dirigem-se no sentido da vedação da degradação das condições ambientais conquistadas, neste caso, das condições socioambientais dos espaços urbanos. Este princípio, qualquer seja a expressão adotada, dirige-se a concretude das condições que garantam minimamente o "existencial ecológico" que deve estar presente nas cidades desde uma perspectiva de efetivação dos princípios da dignidade da pessoa humana e da segurança jurídica. Portanto, em sede de direitos sociais fundamentais, em um Estado Socioambiental e Democrático de Direito, a proibição de retrocesso (ou de retrogradação), vincula a atuação dos poderes públicos da cidade ${ }^{23}$. Nesta perspectiva, e somente nesta, deve-se entender que as cidades são "alguma coisa mais" que os milhares ou milhões de pessoas que as habitam. São maiores que as vicissitudes decorrentes da violência, das neuroses coletivas, das deficiências da malha urbana, da ocupação desordenada dos espaços. As cidades são criações humanas de elevada complexidade de centralização, acumulação e distribuição de conhecimentos, inovações e informações. São também "lugares de acolhida" de variada cultura, e dos saberes plurais de seus habitantes. Mas, acima de tudo as cidades são espaços da existência, cuja densidade física e moral (formatada em uma moralidade pública) produziram como anotou Durkheim ${ }^{24}$,

${ }^{22}$ Cf. KLOEPFER, M., Umweltrechts, 3ª . Aufl. München: Verlag C. H. Beck oHG, 2004 p. 169.

${ }^{23}$ Ingo W. Sarlet (Direitos fundamentais sociais e proibição de retrocesso: algumas notas sobre o desafio da sobrevivência dos direitos sociais num contexto de crise, in, VV. AA., (Neo)Constitucionalismo - ontem, os Códigos hoje, as Constituições, Rev. do Inst. de Hermenêutica Jurídica, v. I, n. 2, Porto Alegre: 2004), com acerto, concluiu que "a proibição de retrocesso assume a condição de um dos mecanismos para a afirmação efetiva de um direito constitucional inclusivo, solidário e altruísta" (p. 163). Um "mecanismo afirmativo" desde tipo levando em consideração que está diretamente subsumido no entrelaçamento de princípios matrizes (dignidade e segurança jurídica), transversalmente, exige dos poderes públicos responsabilidade ambiental, condição para construir mecanismos de solidariedade que devem conduzir todas as relações socioambientais nas cidades.

${ }^{24}$ DURKHEIM, Emile, La división del trabajo social (1893), Madrid: Akal, 1982. 
não só a divisão do trabalho social, mas também a solidariedade orgânica, não fundada nas semelhanças, sim no direito, seus princípios e regras objetiváveis, que são condição da liberdade e da igualdade. Evidentemente esta densidade física e moral embora fortaleça a dependência mútua - provocam a visibilidade das diferenças, colore a luta pela vida nos mais variados matizes, ora encoberta pela obscuridade, ora baixo luminescente foco, onde os processos de diferenciação, divisão e especialização do trabalho e dos habitantes das cidades se dão. Por isso, dizia Lefebvre ${ }^{25}$, que o direito a cidade é o direito a vida humana, transformada, renovada. O direito fundamental à vida sob a garantia do princípio do não retrocesso das condições onde se a exerce, implica o agir do poder público (em todos os níveis da federação), imputando-se um dever de proibição de infraproteção, um de dever dúplice. Uma modalidade especial de dever que, por vezes, implica o "fazer" do Estado, imediatamente vinculado à realização dos direitos fundamentais, ou, um "não fazer", revelado na renúncia de atentar contra estes mesmos direitos, pois cada direito tem um conteúdo prima facie conexo a todas as posições garantidoras dos meios indispensáveis para assegurar a cobertura das necessidades básicas protegidas na ambiência normativa do direito. Sem descurar que cada direito tem, ainda, um conteúdo definitivo interligado por todas as posições do direito prima facie oponível não só ao Legislador, mas à Administração, e que não sejam restringíveis, com base nos critérios explicitados pela proibição de infraproteção ${ }^{26}$. Quando se aponta para a proibição de infraproteção e também para o não retrocesso, há de se ter em conta que os limites de nosso mundo nos dão os limites de nossa linguagem ${ }^{27}$, pois a vida psíquica é um particular modo de vivenciar o espaço relacional que ocupamos como seres humanos, todavia, este vivenciar ocorre pelo diálogo sobre o viver no conversar ${ }^{28}$. O simbólico daí resultante é inafastável ${ }^{29}$.

Ao falarmos do princípio de proibição de retrocesso das conquistas já alcançadas

\footnotetext{
${ }^{25}$ LEFEBVRE, Henri. Le Droit à la Ville. Paris: Édition Anthropos, 1974.

${ }^{26}$ Preferimos traduzir a expressão de Canaris, Untermassverbot, por proibição de infraproteção, ainda que com afronta, bem sabemos, da tradução corrente na doutrina de língua portuguesa, proibição de proteção deficiente ou de proibição de omissão; contudo, não o fazemos por extravagância, sim porque prefixo latino infra-, abaixo, em baixo, em posição inferior, dá bem o sentido da preposição unter, abaixo de, sob, e do adjetivo unter, inferior; e, mass, pretérito de messen, medir, ou do substantivo Mass, dimensão, valor. Assim, a proibição de infraproteção mostra-se na proteção subdimensionada que está em posição inferior à base de uma estrutura protetiva e constitui uma afronta a Constituição.

${ }^{27}$ Aqui seguimos a lição do primeiro Wittgenstein (Tratado Lógico-filosófico, Lisboa: Fundação Calouste Gulbenkian, 1987), sem deixar de levar em consideração a afirmativa do segundo, em sua observação: o significado das palavras não depende do fato a que elas se referem, mas de como elas são utilizadas (Investigações filosóficas, Lisboa: Fundação Calouste Gulbenkian, 1987).

${ }^{28}$ MATURAMA, Humberto. Ontologia da Realidade. Trad. Cristina Magroe Nelson Vaz. Belo Horizonte: Ed. UFMG, 1999.

${ }^{29}$ A propósito, Lorite, leciona: "La especie homo inaugura, en el proceso de la vida, una etapa que se puede caracterizar a través de un rasgo dominante: la creación de un espacio simbólico. Los símbolos, concretados instrumentalmente (ya sea al nivel de objetos, de lenguaje, de normas, creencias, etc.) revisten un carácter mediador y mediatizador entre el hombre y las cosas. En ese espacio se inscribe una dinámica de transformación consciente del contorno vital. Se trata de un cambio cualitativo en la lógica de lo vivo, en cuanto aparición de un nivel de procesamiento del conocimiento en el cual está incluido reflexivamente el individuo que lo practica" (Lorite, M. J., El Animal Paradójico, Fundamentos de Antropología Filosófica. Barcelona: Antropos, 1982, p. 34).
} 
na ambiência das cidades, quer-se afirmar uma proposição empírica, que através de uma eleição valiosa de nossa existência e de uma avaliação intergeracional, não permite ou impede que se retrocedam a condições socioambientais prévias àquelas desfrutadas na atualidade. No entanto, advirta-se, esta proposição está conformada numa linguagem conotativa que expressa uma realidade formada por palavras, por regras de linguagem que delimitam um campo de domínio, de poder. $\mathrm{E}$, neste caso, temos de cuidar para não utilizá-las como arma ideológica; pois, tudo está conectado pela linguagem, e as interações que ocorrem não ocorrem por acaso, mas porque as mínimas unidades significativas de nossa linguagem que estão impregnadas de conteúdo comunicativo, que exercem o papel de ligação entre a realidade e o expressivo. Assim, é muito apropriado dizer que o uso da linguagem está comprometido com a existência dos objetos para os quais há palavras em sua metalinguagem. O princípio de proibição de retrocesso (retrogradação) socioambiental é o sintagma proposicional metalinguístico de todos os demais princípios dos DESCA. Portanto as palavras empregadas para caracterizá-lo não devem conformar atos de poder, mas sim atos de cooperação e solidariedade do ser humano no "lugar de encontro" em que está inserido ${ }^{30}$. Por isso é que denominamos linguagem como ação (ação comprometida). Aí, assume importância a dignidade do humano que é mais restrita que a noção de dignidade da pessoa humana. Tal é assim, pois mesmo a pessoa (persona) que age ou labora de modo intencional no prejuízo do outro neste "lugar de encontro", não perde sua dignidade íntima de "pessoa", apenas faz mais presente sua "máscara", escondendo o seu "rosto". Com a dignidade do humano, as coisas são diferentes. A dignidade do humano é deontológica, revela-se na capacidade de assumir deveres, comprometer-se com o conveniente, com o necessário. Está bem delineada no Art. 29, 1-2, da Declaração de $1948^{31}$. Concretizar os deveres para a comunidade, para o outro neste "lugar de encontro", é o que torna possível o desenvolvimento do ser humano e sua permanência num ambiente saudável. Afirme-se, pois, que o ser humano não pode ser perspectivado tão só desde sua individualidade, e que sua atuação na Sociedade, no Estado, e concretamente na Cidade, diga respeito apenas a sua constelação patrimonial e moral, sem levar em consideração as consequências de sua atuação no espectro comunitário (dever jurídico para com a comunidade reunida em um "lugar de encontro"), aí está desenhado, também, o alcance de proibição de retrocesso socioambiental e de seu objeto, no caso das cidades, a vedação da degradação ambiental do espaço urbano que se revela no espaço existencial da cidadania.

\footnotetext{
${ }^{30}$ Convertido em palavras, o princípio de proibição de retrocesso se revela como extensão perceptual (vale dizer, se relaciona com a experiência sensorial imediata) do objeto que conota; todavia, observe-se que, como palavras, o princípio de proibição de retrocesso socioambiental, não expressa um sentido estrito (sobre o objeto delimitado), nós é que o expressamos por via de nossa conduta, valendo afirmar ainda, que é só através da conduta que interpretamos.

31 "Toda pessoa tem deveres para com a comunidade posto que só nela pode alcançar o livre e pleno desenvolvimento de sua personalidade. No exercício de seus direitos e liberdades, toda pessoa estará sujeita apenas às limitações determinadas pela lei, exclusivamente com o fim de assegurar o devido reconhecimento e respeito dos direitos e liberdades de outrem e de satisfazer às justas exigências da moral, da ordem pública e do bem-estar de uma sociedade democrática".
} 


\section{ALGUMAS REFLEXÕES FINAIS}

Todos los textos son borradores. Los únicos textos definitivos son sólo fruto de la religión o del cansancio.

Jorge L. Borges

(Las Versiones Homéricas)

(1) O direito à cidade e a vedação da degradação dos espaços urbanos, objetiva a condução do ci(dadão)tadino na perspectiva de criação e liberdade, pois constituem valores edificadores de uma comunidade esclarecida, bem como da extensão do humano à realidade percebida e inclusiva de todos os seres da cadeia biótica e dos elementos constitutivos da moldura abiótica, entre eles os distintos componentes que determinam o espaço físico no qual habitam os seres vivos como a água, a temperatura, a luz, o pH, o solo e os nutrientes, a energia, o ar, e ainda as paisagens (inclusiva toda a sua topografia).

(2) Um direito atribuído a um indivíduo revela-se como um direito social, pertencente a todos, pois o processo de transformação e requalificação dos seres humanos, havido nas cidades, leva a uma metodologia da ação social na práxis do exercício do poder coletivo, e das consequentes tomadas de decisões objetivando melhores condições urbanísticas para a convivência. Assim, os direitos humanos, na perspectiva socioambiental, pois atribuídos a um sujeito plural (todos) que se singulariza no individuo (o citadino), cabe nos direitos fundamentais (constitucionais), mas deles efunde pelo seu conteúdo e natureza.

(3) A proteção de um perímetro mínimo ecológico existencial no espaço urbano, vedando-se a degradação pela efetividade do princípio de proibição de retrocesso socioambiental, são as condições nucleares para dar concreta eficácia ao princípio da dignidade humana, não sendo assim qualquer atribuição de dignidade é vazia.

(4) A pedagogia da economia, do direito, da política e da ciência deve estar a serviço deste valor, pois as ciências devem servir a compreensão entre os humanos e o entorno por eles confrontados, e não a sua destruição.

(5) Um Estado Socioambiental e Democrático de Direito, conformado sobre espaços urbanos constitucionalmente identificados, tem por dever privilegiar a promoção e conservação de suas condições socioambientais independentemente da arguição da escassez de recursos, pois sempre existem os meios necessários para a satisfação das necessidades, desde que observadas adequadas políticas de prioridades na sua aplicação.

(6) Políticas de prioridades na utilização dos recursos estatais, e de fomento nas atividades privadas, devem levar em consideração a superação do déficit de execução das normas socioambientais incorporadas nos DESCA, e, de outro modo, evitar um superávit de regulação desordenada, situações que poderão dar ensejo ao surgimento de demandas impossíveis de atendimento na ordem social, ou, ao revés, possibilitar a emergência de um sistema socioambiental ancorado numa descrição imaginativa de uma sociedade ideal, fundamentada em leis adequadas ao objeto regulado, e em instituições político-econômicas verdadeiramente comprometidas com o bem-estar da coletividade. 
(7) À semelhança do direito fundamental ao meio ambiente ecologicamente equilibrado, o direito à cidade nele contido, também se revela como um direito entre gerações, inclusivo e social. Ademais, e pela mesma razão, dá ensejo ao exercício pleno da cidadania e aos pertinentes deveres cometidos ao poder público.

(8) No direito à cidade, a função social dos direitos humanos e dos direitos fundamentais, na perspectiva dos DESCA, e só nesta perspectiva, consiste na reivindicação de igual acesso aos bens socioculturais (aí incluídos a ocupação urbana, a acessibilidade na urbe, à segurança, o lazer, os serviços de saúde, a seguridade social, a educação pública, entre outros), bens estes exercidos e exercíveis nos espaços urbanos, e que devem gozar de especial proteção do Estado, em especial o não retrocesso das condições socioambientais conquistadas, bem como em não retroverter o conteúdo normativo que as alcança.

(9) $\mathrm{O}$ direito à cidade - como direito [humano] fundamental - conforta um direito de proteção por parte do Estado (portanto, uma proibição de infraproteção). Tal proteção conduz na direção de um feixe de deveres, entre outros: o dever de proibição de conduta contrária ao direito; o dever da prestação de segurança contra a injusta intromissão de terceiros; o dever de prevenção e de precaução contra os riscos, especialmente os fluídos da inovação tecnológica; de outro lado, estes deveres atribuem ao ci(dadão)tadino um direito subjetivo público inarredável fundado mesmo na dignidade atribuída não só ao humano, mas ao que pertence a um povo, a uma classe, a um grupo, ademais de ser, como direito, um elemento fundamental da ordem constitucional objetiva.

Por fim,

O direito à cidade não é apenas o direito de acesso ao que já está dado, mas um direito de modificá-la. Um direito que afirma a possibilidade de vivermos de nossas próprias criações. Um direito de refazermo-nos qualitativamente, produzindo um especial tipo de sociabilidade urbana, o que se afirma como um dos mais preciosos de todos os direitos humanos.

\section{REFERÊNCIAS BIBLIOGRÁFICAS}

ÁVILA COIMBRA, J. de. O outro lado do Meio Ambiente. 2. ed. Campinas: Millenium Editora, 2002.

BAUMAN Zigmund. Community: Seeking Safety in an Insecure World. Cambridge: Polity Press, 2001.

BORJA, Jordi. Movimientos sociales urbanos. Buenos Aires: Ediciones Siap-Planteos, 1975. La ciudad conquistada. Madrid: Alianza Editorial, 2003.

Urbanismo en el siglo XXI: Bilbao, Madrid, Valencia, Barcelona. Barcelona: Ediciones UPC, 2004.

CALVINO, Ítalo. Le città invisibili. Milano: Mondadori, 1993.

CANOTILHO, José Joaquim Gomes. Constituição Dirigente e Vinculação do Legislador: contributo para a compreensão das Normas Constitucionais Programáticas, 2. ed. Coimbra: Coimbra Editora, 2001.

DiREITOS FundAMENTAIS $\varepsilon$ J JUSTIÇA N' 10 - JAN./MAR. 2010 
CASTELLS, Manuel. The Rise of the Network Society. Massachusetts: Blackwell Publishers, 1996.

The Informational City is a Dual City: Can It Be Reversed? High Technology and Low-Income Communities: Prospects for the Positive Use of Advanced Information Technology, Massachusetts: MIT Press, 1996.

COTTINO, Paolo. La città imprevista. Il dissenso nell uso dello spazio urbano. Milano: Elèuthera Editrice, 2003.

COURTIS, Christian. La prohibición de regresividad en materia de derechos sociales: apuntes introductorios, in Courtis (comp.), Ni un paso atrás. La prohibición de regresividad en materia de derechos sociales. Buenos Aires: Editores del Puerto, 2006.

CUERDA MONTOYA, José Ángel. Hacia una nueva cultura política, in, Derechos Humanos y Tolerancia, Pablo J. Beltrán de Heredia Iraurgui (coord.), San Sebastian: Real Sociedad Bascongada de Amigos del País, 2000.

DE CONTO, Mario. O princípio da Proibição de Retrocesso Social - Uma análise a partir dos pressupostos da hermenêutica filosófica, Porto Alegre: Livraria do Advogado Editora, 2008.

DERBLI, Felipe. O princípio da proibição de retrocesso social na Constituição de 1988. Rio de Janeiro: Renovar, 2007.

DOWELL-JONES, Mary. Contextualising The International Covenant On Economic, Social And Cultural Rights: Assessing The Economic Deficit. Leiden: Martinus Nijhoff Publishers, 2004.

DURKHEIM, Emile. La división del trabajo social (1893), Madrid: Akal, 1982.

FRANCISCO DIAZ, Andres de. Ciudadanía y Democracia: un enfoque republicano. Madrid: La Catarata, 2006.

JEFFRIES Jr John C.; DARYL Levinson, J. The Non-Retrogression Principle in Constitutional Law, in, California Law Review, vol. 86, n. 6, 1998.

KLOEPFER, M., Umweltrechts, $3^{\mathrm{a}}$. Aufl. München: Verlag C. H. Beck oHG, 2004.

LEFEBVRE, Henri. Le Droit à la Ville. Paris: Édition Anthropos, 1974.

LORITE, M. J., El Animal Paradójico, Fundamentos de Antropología Filosófica. Barcelona: Antropos, 1982.

MARTINS, Patrícia do Couto Villela Abbud. A proibição do retrocesso social como fenômeno jurídico, in: Garcia, Emerson (Coord.). A efetividade dos direitos sociais, Rio de Janeiro: Lumen Juris, 2004.

MATURAMA, Humberto. Ontologia da Realidade. Belo Horizonte: Ed. UFMG, 1999.

MENDONÇA, José Vicente dos Santos. Vedação do retrocesso: o que é e como perder o medo, Revista de Direito da Associação dos Procuradores do Novo Estado do Rio de Janeiro, Rio de Janeiro: Lúmen Juris, 2003. v. XII.

MIRANDA, Jorge. Manual de Direito Constitucional. 5. ed. Coimbra: Coimbra Editora, 2003.

MOLINARO, Carlos Alberto. Direito Ambiental - Proibição de Retrocesso. Porto Alegre: Livraria do Advogado Editora, 2007.

PARK, Robert E., On Social Control and Collective Behavior: Selected Papers (The Heritage of Sociology), Chicago: University of Chicago Press, 1967.

PONTES DE MIRANDA, Francisco C., Sistema de Ciência Positiva do Direito. Tomo IV, Rio de Janeiro, Editor Borsoi: 1972.

QUEIROZ, Cristina. O princípio da não reversibilidade dos direitos fundamentais sociais: princípios dogmáticos e prática jurisprudencial. Coimbra: Coimbra Editora, 2006. 
RODRÍGUEZ, David Eloy. et al. Asombros. Sevilla: Imagoforum, 2006.

SARLET, Ingo Wolfgang. A eficácia dos direitos fundamentais. Uma teoria geral dos direitos fundamentais na perspectiva constitucional. 10. ed. Livraria do Advogado Editora, 2009.

Direitos Fundamentais Sociais e proibição de retrocesso: algumas notas sobre o desafio da sobrevivência dos direitos sociais num contexto de crise, in, VV. AA., (Neo)Constitucionalismo - ontem, os Códigos hoje, as Constituições, Revista do Instituto de Hermenêutica Jurídica. v. I, n. 2, Porto Alegre: 2004.

O Estado Social de Direito, a Proibição de Retrocesso e a Garantia Fundamental da Propriedade. Revista Diálogo Jurídico. Salvador, CAJ-Centro de Atualização Jurídica, v. I, no 4 , julho, 2001. Disponível em: <http:www.direito publico. com.br>, acesso em 12 abr. 2008.

SARMENTO, Daniel. Direitos Fundamentais e Relações Privadas. Rio de Janeiro: Lúmen Júris, 2004.

WITTGENSTEIN, Ludwig. Tratado Lógico-filosófico. Lisboa: Fundação Calouste Gulbenkian, Investigações filosóficas, Lisboa: Fundação Calouste Gulbenkian, 1987. 